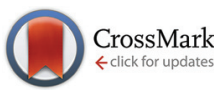

Cite this: Org. Biomol. Chem., 2015, 13,5591

Received 12th March 2015, Accepted 7th April 2015

DOI: 10.1039/c5ob00492f

www.rsc.org/obc

\section{Stereoselective reaction of 2-carboxythioesters- 1,3-dithiane with nitroalkenes: an organocatalytic strategy for the asymmetric addition of a glyoxylate anion equivalent $\dagger$}

\author{
Elisabetta Massolo, ${ }^{a}$ Maurizio Benaglia, ${ }^{\text {a }}$ Andrea Genoni, ${ }^{a}$ Rita Annunziata, ${ }^{a}$ \\ Giuseppe Celentano ${ }^{\mathrm{b}}$ and Nicoletta Gaggero*b
}

\begin{abstract}
An efficient organocatalytic methodology has been developed to perform the stereoselective addition of 2-carboxythioesters-1,3dithiane to nitroalkenes. Under mild reaction conditions $\gamma$-nitro$\beta$-aryl- $\alpha$-keto esters with up to $92 \%$ ee were obtained, realizing a formal catalytic stereoselective conjugate addition of the glyoxylate anion synthon. The reaction products are versatile starting materials for further synthetic transformations; for example, the simultaneous reduction of the nitro group and removal of the dithiane ring was accomplished, allowing the preparation of a $\mathrm{GABA}_{\mathrm{B}}$ receptor agonist baclofen.
\end{abstract}

\section{Introduction}

Chiral $\alpha$-keto esters are considered products of great importance, as starting materials for the preparation of highly functionalized compounds via synthetic manipulation of their functional groups. ${ }^{1}$ They also find successful applications in biochemistry and are an integral part of several biologically active natural compounds. ${ }^{2}$ Therefore, it is not surprising that the stereoselective synthesis of chiral $\alpha$-keto esters is still the object of intense studies. Recently a novel approach was proposed by Johnson, who described a copper(II)-catalyzed aerobic oxidation reaction as a key step for the preparation of $\beta$-substituted $\alpha$-keto esters, in a procedure where acetoacetate esters were used as glyoxylate anion synthons. ${ }^{3}$

However, most of the reported synthesis of chiral $\alpha$-keto esters rely on the umpolung strategy that allows the introduc-

\footnotetext{
a Dipartimento di Chimica, Universita' degli Studi di Milano, via Golgi 19, I-20133 Milano, Italy.E-mail: maurizio.benaglia@unimi.it; Fax: +390250314159

${ }^{b}$ Dipartimento di Scienze Farmaceutiche, Università degli Studi di Milano, via Mangiagalli, 25, Milano, Italy

$\dagger$ Electronic supplementary information (ESI) available: Experimental details for nitrostyrene derivatives synthesis, catalysts preparation and organocatalytic reactions. Characterization details for Michael addition products and Baclofen synthesis. Determination of absolute configuration of the reaction products. ${ }^{1} \mathrm{H}$-NMR, ${ }^{13} \mathrm{C}$-NMR and ${ }^{19} \mathrm{~F}$-NMR spectra and HPLC chromatograms on the chiral stationary phase of addition products. See DOI: 10.1039/c5ob00492f
}

tion of a nucleophilic acyl anion synthon, ${ }^{4} \mathrm{~N}$-heterocyclic carbenes are known for their ability to reverse the polarity of aldehydes, to generate acyl anion equivalents that have been widely employed in benzoin and Stetter-type reactions. ${ }^{5}$ More traditional methods involve the use of metalated aminonitriles ${ }^{6}$ and 1,3-dithiane-protected glyoxylates, ${ }^{7}$ prepared by deprotonation with stoichiometric amounts of a strong base. ${ }^{8}$ It must be noted that all of these methods suffer from intrinsic limitations and problems (limited general applicability, low yields, modest stereoselectivity, and strongly depending on reactant substrates); in addition, examples of direct synthesis of enantiomerically enriched keto esters are still very rare, especially those related to the preparation of enantiopure $\beta$-aryl- $\alpha$-keto esters, where the strong acidity of the proton in the $\beta$ position represents a real issue for any successful stereoselective methodology.

With the goal to develop a metal-free catalytic strategy for the synthesis of chiral $\beta$-substituted- $\alpha$-keto esters, we decided to study the addition of 1,3-dithiane-2-carboxy derivatives to nitroalkenes. Surprisingly, a catalytic stereoselective version of this powerful transformation seems to be unknown. ${ }^{9}$ Here we wish to report the first enantioselective organocatalytic conjugate addition of 2-carboxythioesters-1,3-dithiane to nitroalkenes.

At the beginning of our investigation the chemical reactivity of different 2-carboxyester 1,3-dithianes was investigated in the presence of a cinchona-derived bifunctional catalyst $\mathbf{A}$ (Scheme 1) ${ }^{10}$.

Commercially available 1,3-dithiane-2-ethylcarboxylate 2 in the presence of $20 \mathrm{~mol} \%$ of quinine-thiourea derivative A did not react at all with nitrostyrene. The corresponding $S$-phenyl thioester 4 showed poor reactivity, affording the corresponding addition product 5 in low yields, even after prolonged reaction times, although in a remarkable $89 \%$ enantioselectivity (entries 2 and 3, Table 1). As expected 2-pyridylthioester 6 afforded adduct 7 in higher yields; unfortunately the reaction product turned out to be not very stable, thus preventing the determination of its enantiomeric excess. Finally the use of 


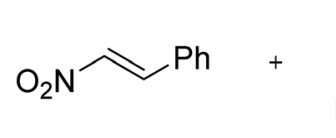

1



$2 x=O E t$

$4 \mathrm{X}=\mathrm{SPh}$

$6 \mathrm{X}=\mathrm{SP} y$

$8 \mathrm{X}=\mathrm{SCH}_{2} \mathrm{CF}_{3}$
$3 \mathrm{X}=\mathrm{OEt}$

$5 \mathrm{X}=\mathrm{SPh}$

$7 \mathrm{X}=\mathrm{SPy}$

$9 \mathrm{X}=\mathrm{SCH}_{2} \mathrm{CF}_{3}$



Scheme 1 Preliminary studies of organocatalytic addition of dithianes to nitrostyrene.

Table 1 Chemical activity of 2-substituted 1,3-dithianes

\begin{tabular}{llllll}
\hline Entry $^{a}$ & $\mathrm{X}$ & Product & $t(\mathrm{~h})$ & Yield $^{b}(\%)$ & $\mathrm{ee}^{c}(\%)$ \\
\hline 1 & $\mathrm{OEt}$ & $\mathbf{3}$ & 24 & - & - \\
2 & $\mathrm{SPh}$ & $\mathbf{5}$ & 24 & 16 & 89 \\
3 & $\mathrm{SPh}$ & $\mathbf{5}$ & 72 & 25 & 87 \\
4 & $\mathrm{SPy}$ & 7 & 24 & 41 & n.d. \\
5 & $\mathrm{SCH}_{2} \mathrm{CF}_{3}$ & $\mathbf{9}$ & 24 & 71 & 87
\end{tabular}

${ }^{a}$ Typical reaction conditions: $0.1 \mathrm{mmol}$ of nitroalkene, $0.2 \mathrm{mmol}$ of dithiane, $0.02 \mathrm{mmol}$ of catalyst $\mathbf{A}, 1 \mathrm{~mL}$ of toluene. ${ }^{b}$ Yields were determined after chromatographic purification. ${ }^{c}$ Enantiomeric excess determined by HPLC on a chiral stationary phase.

2-S-trifluoroethyl carboxy-thioester-1,3-dithiane 8 gave the best results; after 24 hours at RT the stable conjugate addition product 9 was obtained in $71 \%$ yield and $87 \%$ ee. ${ }^{11}$

The use of 1,1,1-trifluoroethyl thioester was documented for the first time by Barbas in an organocatalytic Michael reaction. ${ }^{12}$ Later, our group took advantage of low $\mathrm{p} K_{\mathrm{a}}$ of the protons in the $\alpha$ position of the carboxy group in the trifluoroethyl thioesters to realize the first organocatalytic direct aldol reaction between a thioester and an aromatic aldehyde. ${ }^{13}$ Due to its favorable reactivity profile (entry 5 , Table 1), thioester 8 was selected as a reagent of choice and its addition to nitrostyrene was studied in the presence of different chiral bifunctional organocatalysts (Scheme 2).

In the model reaction performed in toluene for 24 hours at room temperature $2 \mathrm{~mol}$ eq. of thioester 8 were reacted with $1 \mathrm{~mol}$ eq. of nitrostyrene in the presence of $0.2 \mathrm{~mol}$ eq. of a catalyst. Based on the good results obtained with catalyst A, another successful thiourea-based bifunctional catalyst, Takemoto catalyst $\mathbf{B},{ }^{14}$ was tested; the product was isolated in higher yield but lower enantioselectivity than the cinchonaderived catalyst $\mathbf{A}$ (entries 1 and 2 of Table 2, $67 \%$ ee for catalyst B vs. 87\% ee for A).
Therefore we turned our attention to the variation of different structural elements of quinine-derived catalyst $\mathbf{A}$; for example with the cinchonidine derivative $\mathbf{C}$, lacking the methoxy group on the quinolone ring, a little decrease in enantioselection was observed ( $75 \%$ vs. $87 \%)$. A modification of the same alkoxy group was deleterious for enantioselectivity (see entries 4 and 5, catalysts $\mathbf{D}$ and $\mathbf{E}$ ). Compounds F-I clearly demonstrated the crucial role exerted by the thiourea moiety which cannot be replaced by alternative hydrogen bond donor groups. In addition, when squaramides $\mathbf{L}-\mathbf{N},{ }^{15}$ derived from quinine or trans-diamine-cyclohexane, were tested, very low enantioselectivities were obtained.

Once compound $\mathbf{A}$ was selected as a catalyst of choice, a few reaction parameters were optimized (Table 3).

The reaction tolerates different solvents, although only dichloromethane guaranteed the same level of ee as toluene ( $80 \%$ ee at RT). Lowering the reaction temperature to $0{ }^{\circ} \mathrm{C}$ had a positive effect, allowing isolating the product in $92 \%$ ee; lower temperatures did not give satisfactory results. It is noteworthy that the loading of the catalyst could be decreased to $10 \mathrm{~mol} \%$ and even to $5 \mathrm{~mol} \%$ with only a marginal loss of enantioselectivity, albeit with diminished chemical yield. The general applicability of the methodology was then investigated (Scheme 3, eqn (a)).

Differently substituted nitro alkenes were easily prepared ${ }^{11}$ and reacted with dithiane $\mathbf{8}$ in the presence of catalyst $\mathbf{A}$ (Table 4).

The reaction works with nitrostyrenes substituted both in ortho and in para positions, with electron rich or poor substituents, leading to products with enantioselectivities ranging typically between $70 \%$ and $92 \%$. Typically less reactive alkyl nitro alkenes ${ }^{16}$ did not react under the present conditions (entries 10 and 11); however, 4-nitro-1-phenyl butadiene reacted smoothly to afford product $\mathbf{1 7}$, bearing a styryl moiety in $61 \%$ yield and $71 \%$ ee (eqn (b), Scheme 3 ). 
<smiles>C=CC1=CN=C(C(NC(=S)Nc2cc(C(F)(F)F)cc(C(F)(F)F)c2)c2ccnc3ccccc23)C1C1C=NC(C(F)(F)F)C1C=C</smiles><smiles>C=CC1=CN2CCC1C2C(NC(=S)Nc1cc(C(F)(F)F)cc(C(F)(F)F)c1)c1ccnc2ccc(OC(C)C)cc12</smiles><smiles>C=CC1=CN2CC[C@H]1C2C(NC(=S)Nc1cc(C(F)(F)F)cc(C(F)(F)F)c1)c1ccnc2ccc(O)cc12</smiles><smiles>C=CC1=CN2CCC1CC2[C@H](O)c1ccnc2ccc(OC)cc12</smiles><smiles>C=CC1=CN2CCC1C2[C@H](O)c1ccnc2ccc(O)cc12</smiles><smiles>C=CC1CN2CCC1CC2C(N)c1ccnc2ccc(OC)cc12</smiles><smiles>C=CC1=CN2CCC1C2C(N)c1ccnc2ccc(O)cc12</smiles>

F

G

H

I<smiles>C=CC1CC2CCN1CC2[C@@H](Nc1c(OC)c(=O)c1=O)c1ccnc2ccc(OC)cc12</smiles><smiles>C=CC1CC2CCN1CC2[C@H](Nc1c(NC(c2ccnc3ccc(OC)cc23)c2ccnc3ccc(OC)cc23)c(=O)c1=O)C1CC2CCN1CC2</smiles><smiles>CN(C)C1CCCC[C@H]1Nc1c(Nc2cc(C(F)(F)F)cc(C(F)(F)F)c2)c(=O)c1=O</smiles>

L

Scheme 2 Chiral organocatalysts investigated in the 1,3-dithiane addition to nitrostyrene.

Table 2 Screening of chiral organocatalysts in the 1,3-dithiane addition to nitrostyrene



\begin{tabular}{llll}
\hline Entry $^{a}$ & Catalyst & $\operatorname{Yield}^{b}(\%)$ & ee $^{c}(\%)$ \\
\hline 1 & A & 71 & 87 \\
2 & B & 81 & 67 \\
3 & C & 55 & 75 \\
4 & D & 53 & 51 \\
5 & E & 41 & 37 \\
6 & F & 53 & $<5$ \\
7 & G & 55 & 31 \\
8 & H & 73 & 37 \\
9 & I & 15 & $<5$ \\
10 & L & 51 & 21 \\
11 & M & 47 & 7 \\
12 & N & 57 & $<5$
\end{tabular}

${ }^{a}$ Typical reaction conditions: $0.1 \mathrm{mmol}$ of nitroalkene, $0.2 \mathrm{mmol}$ of dithiane, $0.02 \mathrm{mmol}$ of catalyst $\mathbf{A}, 1 \mathrm{~mL}$ of toluene. ${ }^{b}$ Yields were determined after chromatographic purification. ${ }^{c}$ Enantiomeric excess determined by HPLC on a chiral stationary phase.
Table 3 Solvent screening for the organocatalyzed addition of dithiane 8 to nitrostyrene

\begin{tabular}{llcll}
\hline Entry $^{a}$ & Solvent & Temp. $\left({ }^{\circ} \mathrm{C}\right)$ & Yield $^{b}(\%)$ & ee $^{c}(\%)$ \\
\hline 1 & Toluene & 25 & 71 & 87 \\
2 & DCM & 25 & 55 & 80 \\
3 & $\mathrm{CH}_{3} \mathrm{CN}$ & 25 & 80 & 41 \\
4 & Hexane & 25 & 75 & 57 \\
5 & Et $2 \mathrm{O}$ & 25 & 73 & 67 \\
6 & Toluene & 0 & 60 & 92 \\
7 & Toluene & -20 & 61 & 66 \\
$8^{d}$ & Toluene & 25 & 55 & 81 \\
$9^{e}$ & Toluene & 25 & 47 & 80
\end{tabular}

${ }^{a}$ Typical reaction conditions: $0.1 \mathrm{mmol}$ of nitroalkene, $0.2 \mathrm{mmol}$ of dithiane, $0.02 \mathrm{mmol}$ of catalyst $\mathbf{A}, 1 \mathrm{~mL}$ of toluene. ${ }^{b}$ Yields were determined after chromatographic purification ${ }^{c}$ Enantiomeric excess determined by HPLC on a chiral stationary phase. ${ }^{d}$ Reaction run with $10 \mathrm{~mol} \%$ of a catalyst. ${ }^{e}$ Reaction run with $5 \mathrm{~mol} \%$ of a catalyst.

In order to establish the absolute configuration of the addition products, compound $\mathbf{1 1}$ was treated with powdered zinc and $6 \mathrm{M} \mathrm{HCl}^{17}$ to afford enantiomerically enriched lactam 
eq. a)

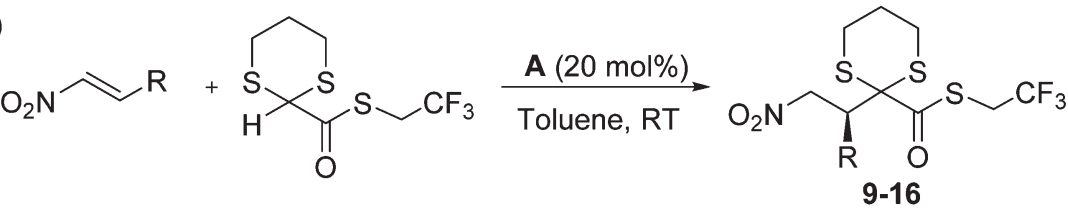

eq. b)

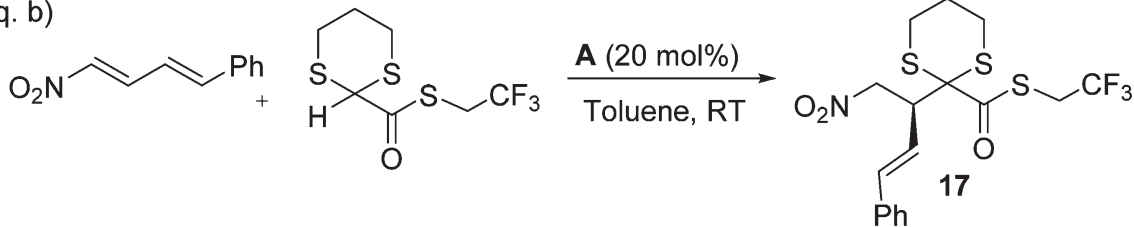

Scheme 3 Organocatalytic 1,3-dithiane addition to different nitroalkenes.

Table 4 General applicability of the catalytic methodology

\begin{tabular}{lllll}
\hline Entry $^{a}$ & $\mathrm{R}$ & Product & Yield $^{b}(\%)$ & $\mathrm{ee}^{c}(\%)$ \\
\hline 1 & $\mathrm{Ph}$ & $\mathbf{9}$ & 71 & 87 \\
$2^{d}$ & $\mathrm{Ph}$ & $\mathbf{9}$ & 60 & 92 \\
3 & $4-\mathrm{CF}_{3} \mathrm{Ph}$ & $\mathbf{1 0}$ & 41 & 53 \\
4 & $4-\mathrm{ClPh}$ & $\mathbf{1 1}$ & 81 & 86 \\
5 & $4-\mathrm{CH}_{3} \mathrm{Ph}$ & $\mathbf{1 2}$ & 71 & 73 \\
6 & $2-\mathrm{CH}_{3} \mathrm{Ph}$ & $\mathbf{1 3}$ & 43 & 67 \\
7 & $4-\mathrm{OCH}_{3} \mathrm{Ph}$ & $\mathbf{1 4}$ & 75 & 73 \\
8 & $2-\mathrm{OCH}_{3} \mathrm{Ph}$ & $\mathbf{1 5}$ & 80 & 71 \\
9 & $2-\mathrm{OAcPh}$ & $\mathbf{1 6}$ & 55 & 85 \\
10 & $\mathrm{i}-\mathrm{Pr}_{11}$ & n.r. & - & - \\
& $\mathrm{CH}_{2} \mathrm{CH}_{2} \mathrm{Ph}$ & n.r. & - & -
\end{tabular}

${ }^{a}$ Typical reaction conditions: $0.1 \mathrm{mmol}$ of nitroalkene, $0.2 \mathrm{mmol}$ of dithiane, $0.02 \mathrm{mmol}$ of catalyst $\mathrm{A}, 1 \mathrm{~mL}$ of toluene at $25{ }^{\circ} \mathrm{C} .{ }^{b}$ Yields were determined after chromatographic purification. ${ }^{c}$ Enantiomeric excess determined by HPLC on a chiral stationary phase. ${ }^{d}$ Reaction run at $0^{\circ} \mathrm{C}$.
18, which was determined to be in the $(S)$ configuration by comparison of optical rotation power values. Indeed final hydrolysis with hydrochloridric acid afforded $(S)$-baclofen 19 (Scheme 4). ${ }^{18}$

Therefore, the method offers a straightforward access to a direct precursor of baclofen-type derivatives, $\mathrm{GABA}_{\mathrm{B}}$ receptor agonists used in the treatment of spasticity and alcohol dependence. $^{19}$

Finally, conversion of the addition products into the corresponding $\alpha$-ketothioesters was achieved by reaction with $\mathrm{N}$-bromosuccinimide in acetone (Scheme 5). ${ }^{20}$

For example, compounds 9-11 were quantitatively converted to $\alpha$-ketothioesters 20-22. Interestingly, upon treatment of 20-22 with silver trifluoroacetate, $\beta$-nitro esters 23-25 were obtained (Scheme 5). ${ }^{21}$<smiles>NC[C@H](CC(=O)O)c1ccc(Cl)cc1</smiles>

Scheme 4 Synthesis of baclofen.

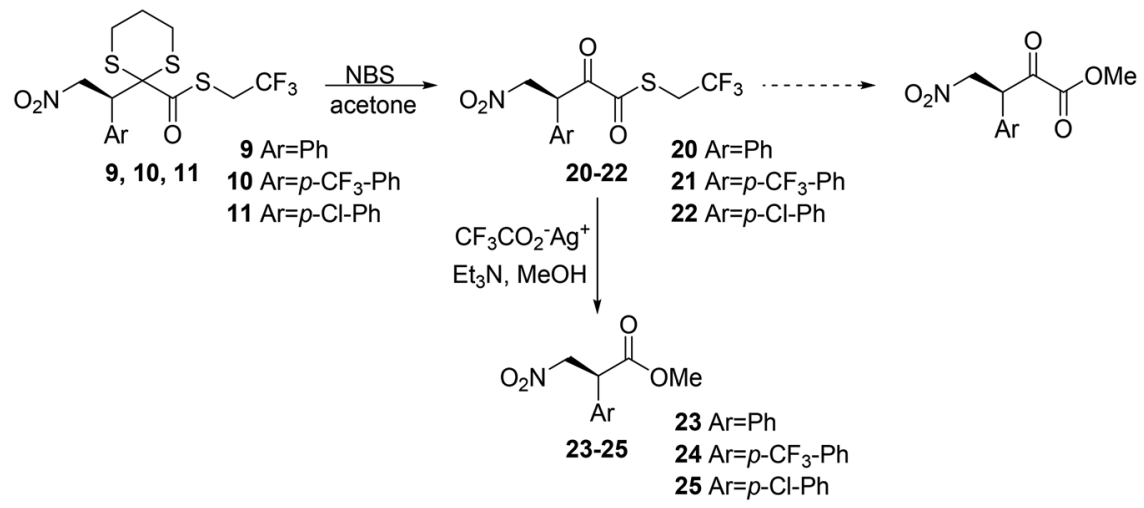

Scheme 5 Synthesis of $\beta$-aryl- $\alpha$-keto thioesters. 


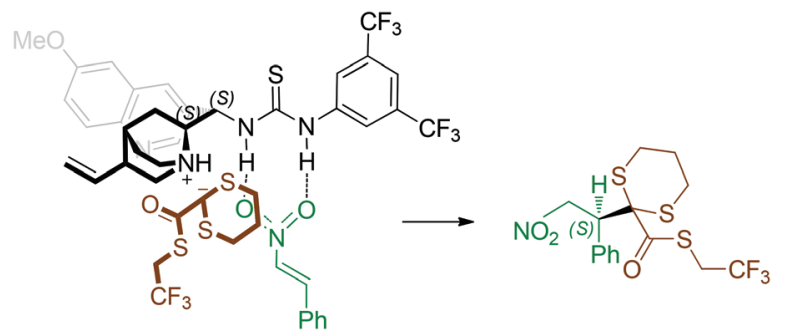

Fig. 1 Proposed stereoselection model.

The procedure afforded compounds 20-22 without affecting the stereochemical integrity of the starting materials. For instance, a sample of $(R)-9(53 \%$ ee) was quantitatively transformed into $\alpha$-ketothioester 20 through a 4 hour reaction with NBS in acetone at $0{ }^{\circ} \mathrm{C}$, and then reacted with $\mathrm{CF}_{3} \mathrm{CO}_{2} \mathrm{Ag}$ in methanol to give the known $(R)$ - $\beta$-nitro methylester $23^{22}$ in $70 \%$ yield, its absolute configuration reflecting that of the starting compound $\mathbf{9}$ without appreciable variation of the enantiomeric excess. ${ }^{23}$

In proposing a stereoselection model, the coordination of both reaction partners to the bifunctional catalyst may be envisaged, the substrate nitro group being engaged in hydrogen bonds by the thiourea moiety, and the charged quinuclidine nitrogen possibly forming an ion pair with the nucleophile (Fig. 1).

Accordingly, with the quinine-derived catalyst, the thioester attack occurs on the nitroalkene $S i$ face, affording the experimentally observed $(S)$-configured product.

In conclusion, the enantioselective organocatalyzed conjugate addition of a newly activated thioester acting as an acyl anion mimic has been performed. The use of chiral bifunctional catalysts to control the stereochemical outcome through a hydrogen bond network imposed by the thiourea moiety afforded good yields and enantioselectivities up to $92 \%$. This methodology represents an entry to highly functionalized, enantiomerically enriched products, such as $\gamma$-nitro- $\beta$-aryl$\alpha$-keto thioesters, valuable precursors of a wide variety of chiral organic compounds.

\section{Acknowledgements}

M. B. thanks COST action CM9505 "ORCA" Organocatalysis. E. M. and A. G. thank the University of Milan for PhD fellowships.

\section{References}

1 A review: M. Shibasaki and M. Kanai, Chem. Rev., 2008, 108, 2853. See also: Q. Kang, Z. A. Zhao and S. L. You, Adv. Synth. Catal., 2007, 349, 1657.

2 M. J. Kiefel and M. von Itzstein, Chem. Rev., 2002, 102, 471. See also: S. Hanessian, Total Synthesis of Natural
Products: The Chiron Approach, Pergamon Press, New York, 1983, ch. 2.

3 K. M. Steward and J. S. Johnson, Org. Lett., 2011, 13, 2426. See also: M. W. Leighty, B. Shen and J. N. Johnston, J. Am. Chem. Soc., 2012, 134, 15233. For a similar approach in the synthesis of chiral ketones through catalytic oxidative $\mathrm{C}-\mathrm{C}$ bond cleavage of aldehydes by oxygen, see: B. Tiwari, J. Zhang and Y. R. Chi, Angew. Chem., Int. Ed., 2012, 51, 1911.

4 (a) D. Seebach, Angew. Chem., Int. Ed., 1979, 18, 239. For a review on organocatalytic umpolung, see: $(b) \mathrm{X}$. Bugaut and F. Glorius, Chem. Soc. Rev., 2012, 41, 3511. For some recent papers on organocatalytic additions of acyl anion synthons, see: (c) T. Hashimoto, M. Hirose and K. Maruoka, J. Am. Chem. Soc., 2008, 130, 7556; (d) M. Rueping, E. Sugiono, T. Theissman, A. Kuenkel, A. Kiickritz, A. Pews-Davtyan, N. Nemati and M. Beller, Org. Lett., 2007, 1065; (e) B. Alonso, E. Reyes, L. Carillo, J. L. Vicario and D. Badia, Chem. - Eur. J., 2011, 17, 6048; (f) M. Fernández, U. Uria, J. L. Vicario, E. Reyes and L. Carrillo, J. Am. Chem. Soc., 2012, 134, 11872; (g) D. Monge, A. M. Crespo-Peña, E. Martín-Zamora, E. Álvarez, R. Fernández and J. M. Lassaletta, J. Am. Chem. Soc., 2012, 134, 12912; (h) A. M. Crespo-Peña, D. Monge, E. Martín-Zamora, E. Álvarez, R. Fernández and J. M. Lassaletta, Chem. - Eur. J., 2013, 19, 8421.

5 Reviews: (a) D. Enders, O. Niemeier and A. Henseler, Chem. Rev., 2007, 107, 5606; (b) H. U. Vora, P. Wheleer and T. Rovis, Adv. Synth. Catal., 2012, 354, 1617; (c) X. Bugaut and F. Glorius, Chem. Soc. Rev., 2012, 41, 3511. For more recent contributions, see: (d) O. Bortolini, G. Fantin, V. Ferretti, M. Fogagnolo, P. P. Giovannini, A. Masso, S. Pacifico and D. Ragno, Adv. Synth. Catal., 2013, 355, 3244 and references cited therein; (e) M. M. D. Wilde and M. Gravel, Angew. Chem., Int. Ed., 2013, 52, 12651. See also the review: S. J. Ryan, L. Candish and D. W. Lupton, Chem. Soc. Rev., 2013, 42, 4906.

6 D. Enders, M. Bonten and G. Raabe, Angew. Chem., Int. Ed., 2007, 46, 2314. For a recent contribution, see: K. S. Yang, A. E. Nibbs, Y. E. Turkmen and V. H. Rawal, J. Am. Chem. Soc., 2013, 135, 16050. See also: P. A. Evans, S. Oliver and J. J. Chae, J. Am. Chem. Soc., 2012, 134, 19314.

7 limited examples, see: (a) M. Amat, M. Perez, N. Llor and J. Bosch, Org. Lett., 2002, 4, 2787; (b) I. Coldham, K. M. Crapnell, J.-C. Fernandez, J. D. Moseley and R. Rabot, J. Org. Chem., 2002, 67, 6181; (c) T. Ichige, A. Miyake, N. Kanoh and M. Nakata, Synlett, 2004, 1686 and references cited therein.

8 For a recent catalytic, non-stereoselective, conjugate addition of acyl anion equivalents derived from 2-silyl-1,3dithianes to unsaturated ketones, see: S. E. Denmark and L. R. Cullen, Org. Lett., 2014, 16, 70. For a Pd-catalyzed coupling of acetyltrimethylsilane, see: S. Ramgren and N. K. Garg, Org. Lett., 2014, 16, 824.

9 For a review of organocatalytic asymmetric conjugate addition, see: (a) D. Enders, C. Wang and J. X. Liebich, 
Chem. - Eur. J., 2009, 15, 11058; (b) S. Sulzer-Mosse' and A. Alexakis, Chem. Commun., 2007, 3123; (c) D. Roca-Lopez, D. Sadaba, I. Delso, R. P. Herrera, T. Tejero and P. Merino, Tetrahedron: Asymmetry, 2010, 21, 2561. Recent contributions: (d) D. Uraguchi, Y. Ueki and T. J. Ooi, Chem. Sci., 2012, 3, 842 and; (e) G. K. S. Prakash, F. Wang, Z. Zhang, C. Ni, R. Haiges and G. A. Olah, Org. Lett., 2012, 14, 3260.

10 (a) L.-Q. Lu, X.-L. An, J.-R. Chen and W.-J. Xiao, Synlett, 2012, 490; (b) O. V. Serdyuk, C. M. Heckel and S. B. Tsogoeva, Org. Biomol. Chem., 2013, 11, 7051; (c) Y. Xi and X. Shi, Chem. Commun., 2013, 8583.

11 As expected, the reaction performed in the presence of the "quasi" enantiomeric catalyst derived from quinine afforded the addition product with the opposite absolute configuration, in comparable yield (67\%) and marginally lower enantioselectivity ( $83 \%$ ee).

12 D. A. Alonso, S. Kitagaki, N. Utsumi and C. F. Barbas, Angew. Chem., Int. Ed., 2008, 47, 4588.

13 (a) S. Rossi, M. Benaglia, F. Cozzi, A. Genoni and T. Benincori, Adv. Synth. Catal., 2011, 353, 848; (b) M. Bonsignore, M. Benaglia, F. Cozzi, A. Genoni, S. Rossi and L. Raimondi, Tetrahedron, 2012, 68, 8251.
14 T. Okino, Y. Hoashi and Y. Takemoto, J. Am. Chem. Soc., 2003, 135, 12672. Review: Y. Takemoto, Org. Biomol. Chem., 2005, 3, 4299.

15 Review: J. Aleman, A. Parra, H. Jiang and K. A. Jørgensen, Chem. - Eur. J., 2011, 17, 689.

16 For a theoretical work on nitroalkenes reactivity, see: V. Rai and I. N. N. Namboothiri, Eur. J. Org. Chem., 2006, 4693.

17 T. Okino, Y. Hoashi, T. Furukawa, X. Xu and Y. Takemoto, J. Am. Chem. Soc., 2005, 127, 119.

18 By employing $(R, R)$-diaminocyclohexane-derived catalyst $\mathbf{B}$ addition products of the $(R)$-configuration are obtained.

19 H. Gotoh, H. Ishikawa and Y. Hayashi, Org. Lett., 2007, 9, 5307 and references cited therein.

20 E. J. Corey and B. W. Erickson, J. Org. Chem., 1971, 36, 3553.

21 This approach accesses enantiomerically enriched $\beta$-substituted $\beta$-nitro esters starting from readily available $\beta$-nitroalkenes. The exact mechanism of the metal-promoted decarboxylation reaction is currently under study.

22 H. Liu, J. Xu and D. M. Du, Org. Lett., 2007, 9, 4725.

23 See the ESI $\uparrow$ for HPLC traces. 